\title{
Nitrogen Doped Graphene Nickel Ferrite Magnetic Photocatalyst for the Visible Light Degradation of Methylene Blue
}

\author{
Rajinder Singh, Jigmet Ladol, Heena Khajuria and Haq Nawaz Sheikh*
}

\author{
Department of Chemistry, University of Jammu, Jammu Tawi,180 006 India \\ * Corresponding author: E-mail: hnsheikh@ rediffmail.com
}

Received: 14-10-2016

\begin{abstract}
A facile approach has been devised for the preparation of magnetic $\mathrm{NiFe}_{2} \mathrm{O}_{4}$ photocatalyst $\left(\mathrm{NiFe}_{2} \mathrm{O}_{4}-\mathrm{NG}\right)$ supported on nitrogen doped graphene (NG). The $\mathrm{NiFe}_{2} \mathrm{O}_{4}-\mathrm{NG}$ composite was synthesized by one step hydrothermal method. The nanocomposite catalyst was characterized by Powder X-ray diffraction (PXRD), Scanning electron microscopy (SEM), Transmission electron microscopy (TEM), Fourier transform infrared spectroscopy (FTIR), Ultraviolet-visible spectroscopy (UV-Vis) and Vibrating sample magnetometry (VSM). It is found that the combination of $\mathrm{NiFe}_{2} \mathrm{O}_{4}$ nanoparticles with nitrogen-doped graphene sheets converts $\mathrm{NiFe}_{2} \mathrm{O}_{4}$ into a good catalyst for methylene blue (MB) dye degradation by irradiation of visible light. The catalytic activity under visible light irradiation is assigned to extensive movement of photogenerated electron from $\mathrm{NiFe}_{2} \mathrm{O}_{4}$ to the conduction band of the reduced NG, effectively blocking direct recombination of electrons and holes. The $\mathrm{NiFe}_{2} \mathrm{O}_{4}$ nanoparticles alone have efficient magnetic property, so can be used for magnetic separation in the solution without additional magnetic support.
\end{abstract}

Keywords: Nanostructures, photodegradation, nickel ferrite, catalysts, absorption, UV/Vis spectroscopy.

\section{Introduction}

Photocatalysis especially by $\mathrm{TiO}_{2}$ has been widely used for the purification of waste water. The energy band gap of $3.2 \mathrm{eV}$ is required for the excitation of electron by light in $\mathrm{TiO}_{2}$ catalyst so UV light can only be used in the process of photodegradation. The development of visible light sensitive photocatalysts by band gap modifications and external surface changing for waste water treatment and degradation of organic dye is an active area in photocatalysis. ${ }^{1-7}$ Graphene has attracted the attention due to various applications. ${ }^{8-11}$ Graphene has $\mathrm{sp}^{2}$ hybridized carbon and one atom thick (2-D) sheet of conjugated system and extraordinary physical and chemical properties. ${ }^{12-16}$ There has been so much focus to develop graphene-metal oxide photocatalysts such as $\mathrm{TiO}_{2}$-graphene and $\mathrm{ZnO}$ graphene for the photodegradation of organic dye by the irradiation of visible light. ${ }^{17-22}$ The heterogeneous systems are mostly used to perform the photodegradation reactions. The repeated use of photocatalysts after degradation is of great importance for sustainable use of the catalyst. The magnetic nanoparticles anchored on solid sup- port serve as heterogenous catalyst allowing facile separation of catalyst from reaction products. ${ }^{23}$ Superparamagnetic copper ferrite-graphene nanocomposite prepared via hydrothermal method acts as excellent catalyst for the reduction of nitroarenes. The big advantage of the catalyst is that it can be easily recovered and retains the catalytic activity even after five catalytic cycles. ${ }^{24}$ Copper-cobalt ferrites prepared by hydrothermal method from co-precipated precursor serve as efficient catalyst in the decomposition of methanol to $\mathrm{CO}$ and $\mathrm{H}_{2}{ }^{25}$ The various metal ferrites have been used as catalysts in phenols decomposition, detoxification of $\mathrm{CO}$ gas from automobile exhaust, anodic material for lithium ion batteries. ${ }^{26-29}$ Nickel ferrite (Ni$\mathrm{Fe}_{2} \mathrm{O}_{4}$ ) has the inverse spinel structure. The ferrimagnetism arises due to antiparallel spin of $\mathrm{Fe}^{3+}$ ions present at tetrahedral sites and $\mathrm{Ni}^{2+}$ occupying octahedral sites. ${ }^{30}$ The Nickel ferrite is considered as the efficient magnetic material which has good electrical resistivity, high-Curie temperature and chemical stability. Magnetic nanoparticles of nickel ferrite have been used to manufacture titaniacoated nickel ferrite, which can act as magnetically separable photocatalyst. ${ }^{31}$ The $\mathrm{TiO}_{2}$ doped $\mathrm{NiFe}_{2} \mathrm{O}_{4}$ nanopar- 
ticles possess band gap of $2.19 \mathrm{eV}$ and have displayed enhanced photocatalytic activity as compared to $\mathrm{TiO}_{2}$ for degradation of Rhodamine $\mathrm{B}$ dye in aqueous solution under visible light irradiation. ${ }^{32}$ Pure nickel ferrite is photo-catalytically inactive but its composite with another semiconductor (e.g., graphene sheets) can find an effective mechanism for separation of charges leading to increased photocatalytic performance. One such example is $\mathrm{Zn}$ $\mathrm{Fe}_{2} \mathrm{O}_{4}$-graphene photocatalyst and its great performance in the photocatalytic degradation of MB under visible light irradiation. ${ }^{33}$ Carbon material doped with a heteroatom, such as B, N or S, can increase the pseudo capacitance by manipulating its electronic properties and chemical reactivity leading to increased performance of doped grapheme. ${ }^{34-37}$ Nitrogen-doped graphene (NG) has great utility because of its higher specific capacitance matched to the pristine graphene and good durability, therefore, enabling its use as electrode materials for supercapacitors and applications in photocatalysis. ${ }^{38}$

In this paper, we report the development of one step method to design magnetically separable nitrogen doped graphene-based photocatalyst having excellent catalytic activity. The approach is designed to deposit $\mathrm{NiFe}_{2} \mathrm{O}_{4}$ nanocrystals on nitrogen doped graphene sheets via a onestep hydrothermal method. Interestingly, in the presence of nitrogen doped graphene, the inert nanocrystals of Ni$\mathrm{Fe}_{2} \mathrm{O}_{4}$ have been converted into a highly efficient catalyst for the methylene blue (MB) degradation under visible light irradiation. In addition, $\mathrm{NiFe}_{2} \mathrm{O}_{4}$ nanoparticles themselves have a magnetic property, which makes the Ni$\mathrm{Fe}_{2} \mathrm{O}_{4}-\mathrm{NG}$ composite magnetically separable in liquid medium.

\section{Experimental}

\section{1. Materials}

Iron(III) nitrate nonahydrate $\mathrm{Fe}\left(\mathrm{NO}_{3}\right)_{3} \cdot 9 \mathrm{H}_{2} \mathrm{O}$, Nickel(II) nitrate hexahydrate $\mathrm{Ni}\left(\mathrm{NO}_{3}\right)_{2} \cdot 6 \mathrm{H}_{2} \mathrm{O}$, graphite powder flakes, phosphoric acid and hydrogen peroxide were purchased from Alfa Aesar. All chemicals were used as received without further purification. Ethanol, urea, sodium hydroxide and sulphuric acid were purchased from Sigma Aldrich. Deionized water was used throughout.

\section{2 .2. Synthesis of Magnetic $\mathrm{NiFe}_{2} \mathrm{O}_{4}$-Nitrogen Doped Graphene Composite Photocatalyst}

Purified natural graphite was used for the synthesis of graphene oxide (GO) by the well known method given by Hummers and Offeman. ${ }^{39}$ The graphene oxide (GO) $(0.08 \mathrm{~g})$ was dispersed in $20 \mathrm{ml}$ of absolute ethanol and sonicated for $45 \mathrm{~min}$. In a separate beaker $0.28 \mathrm{~g}$ of $\mathrm{Ni}\left(\mathrm{NO}_{3}\right)_{2} \cdot 6 \mathrm{H}_{2} \mathrm{O}$ and $0.78 \mathrm{~g}$ of $\mathrm{Fe}\left(\mathrm{NO}_{3}\right)_{3} \cdot 9 \mathrm{H}_{2} \mathrm{O}$ mixture was added to $10 \mathrm{ml}$ absolute ethanol with constant stirring for 30 min forming homogenous solution. The two solutions were mixed and $\mathrm{pH}$ of the mixture solution was kept 10.0 using $6 \mathrm{M} \mathrm{NaOH}$ solution and then $1 \mathrm{~g}$ urea was added into it. The resulting mixture was put into a $50 \mathrm{~mL}$ Teflon-lined stainless steel autoclave and heated to $180{ }^{\circ} \mathrm{C}$ for $18 \mathrm{~h}$ in an oven. After cooling the reaction mixture to room temperature and the precipitates were filtered, washed with distilled water and dried in oven at $70{ }^{\circ} \mathrm{C}$ for 12 h. The product was named as $\mathrm{NiFe}_{2} \mathrm{O}_{4}-\mathrm{NG}$. Same method was applied to synthesize pure $\mathrm{NiFe}_{2} \mathrm{O}_{4}$ with the modification that GO and urea were excluded. Sulfur was estimated as $\mathrm{BaSO}_{4}$ by gravimetric method and Chloride was estimated as $\mathrm{AgCl}$ by Volhard's method. ${ }^{40}$

\subsection{Spectroscopic and Microscopic Measurements}

The phase and size of the as-prepared samples were determined from powder X-ray diffraction (PXRD) using D8 X-ray diffractometer (Bruker) at a scanning rate of $12^{\circ}$ $\mathrm{min}^{-1}$ in the $2 \theta$ range from $10^{\circ}$ to $70^{\circ}$, with $\mathrm{Cu} \mathrm{K \alpha}$ radiation $(\lambda=0.15405 \mathrm{~nm})$. Scanning electron microscopy (SEM) micrographs of the samples were recorded on FEI Nova Nano SEM 450. High Resolution Transmission Electron Microscopy (HRTEM) was recorded on Tecnai G2 20 S-TWIN Transmission Electron Microscope with a field emission gun operating at $200 \mathrm{kV}$. The samples for TEM measurements were prepared by evaporating a drop of the colloid onto a carbon coated copper grid. The infrared spectra were recorded on Shimadzu Fourier Transform Infrared Spectrometer (FT-IR) over the range of wave number $4000-400 \mathrm{~cm}^{-1}$ and the standard $\mathrm{KBr}$ pellet technique was employed. The magnetic moment as a function of applied field was recorded using Vibrating Sample Magnetometer (VSM), Lakeshore 7410. All the measurements were performed at room temperature.

\section{4. Photocatalytic Activity Measurement}

The catalytic activity of the as synthesized sample was performed by degradation of organic dye MB under the irradiation of visible light. For the Photo irradiation $500 \mathrm{~W}$ xenon lamp was used fitted with UV cut-off filters (JB450) in order to completely remove any radiation below $420 \mathrm{~nm}$ ensuring the exposure to only visible light. The whole procedure was performed at $25^{\circ} \mathrm{C}$. A $100 \mathrm{~mL}$ of MB dye solution was prepared ( $20 \mathrm{mg} / \mathrm{L}$ concentration) and $0.025 \mathrm{~g}$ of photocatalyst was mixed with dye solution. The resulting mixture was stirred for $60 \mathrm{~min}$ before illumination in order to establish the adsorption - desorption equilibrium between MB and catalyst surface. At same instant of time $5 \mathrm{~mL}$ of dye-catalyst mixture was taken out and concentration of the residual dye was determined with the help of UV-vis spectroscopy by measuring the absorption at $664 \mathrm{~nm}$. The absorbance of dye at $664 \mathrm{~nm}$ was monitored with time after fixed intervals of time. The absor- 
bance of dye with time without catalyst was also recorded for reference.

\section{Results and Discussion}

\section{1. PXRD Measurements}

The structural characterization of the nanoparticles has been carried out by Powder X-ray diffraction technique using $\mathrm{CuK} \alpha$ radiation. Figure $1(\mathrm{a}-\mathrm{b})$ show the differences of phase composition between GO and NG. The doping of nitrogen in GO can be clarified easily by PXRD spectrum. The PXRD pattern of GO exhibits a characteristic (002) peak of graphite emerging at $24.2^{\circ}$. Compared with GO, it is found that the (002) peak of NG appears at $26.3^{2}$ which indicates that nitrogen atoms have entered into the crystal lattice of graphite and caused the increased distance between the graphite layers. This confirms the formation of nitrogen-doped graphene by urea assisted hydrothermal reaction. Figures $1 \mathrm{c}$, d show the PXRD diffraction patterns of the pure $\mathrm{NiFe}_{2} \mathrm{O}_{4}$ and as prepared Ni$\mathrm{Fe}_{2} \mathrm{O}_{4}$-NG. The diffraction peaks at $30.9^{\circ}, 35.7^{\circ}, 43.4^{\circ}$, $53.7^{\circ}, 57.2^{\circ}$ and $63.2^{\circ}$ corresponding to the planes (220), (311), (400), (422), (511) and (440) are allocated to spinel-type $\mathrm{NiFe}_{2} \mathrm{O}_{4}$ (JCPDS No. 54-0964). ${ }^{41}$ Similar diffraction patterns are observed for $\mathrm{NiFe}_{2} \mathrm{O}_{4}-\mathrm{NG}$. The nitrogen doped graphene oxide can be reduced by the alcohol under hydrothermal conditions and no peak at (002) is observed in the composite. It can also be related to well exfoliation of the NG sheets in the resulting composite material. So the diffraction pattern of NG disappears in the XRD pattern of $\mathrm{NiFe}_{2} \mathrm{O}_{4}-\mathrm{NG}$.

The average crystallite size of these nanoparticles was calculated according to the Scherrer's equation.

$$
\beta=\frac{k \lambda}{L \operatorname{Cos} \theta}
$$

where, $\mathrm{L}(\mathrm{nm})$ is the crystallite size, $\lambda(\mathrm{nm})$ is the wavelength of the $\mathrm{Cu} \mathrm{K} \alpha$ radiant, $\lambda=0.15405 \mathrm{~nm}, \beta\left(^{\circ}\right)$ is the full-width at half-maximum (FWHM) of the diffraction peak, $\theta$ is the diffraction angle and $K$ is the Scherrer constant equal to 0.89 . All the major peaks were used to calculate the average crystallite size of the $\mathrm{NiFe}_{2} \mathrm{O}_{4}$ and Ni$\mathrm{Fe}_{2} \mathrm{O}_{4}-\mathrm{NG}$ nanoparticles. The estimated average crystallite sizes of nanoparticles are in the range of $80-120 \mathrm{~nm}$.

\section{2. SEM and TEM Analysis}

Figure 2a shows representative scanning electron microscopy and transmission electron microscopy images of the prepared GO. From the SEM image, morphology and structure of as-prepared graphene oxide sample was investigated. GO sheets were cast on a gold coated (100 nm) $\mathrm{Si} / \mathrm{SiO}_{2}$ substrate. It has been found that the graphene flakes have wrinkled surfaces. Furthermore, in the TEM image (Figure 3a) GO shows layer-by-layer stacked structure and has wrinkled paper like morphology. Such morphological changes can be attributed to the increased formation of phenolic and epoxy functional groups on the basal plane of GO. The curled and overlapped nanosheets can be clearly observed. The SEM image (Figure $2 b$ ) and TEM image (Figure $3 b$ ) reveal that nitrogen-doped grapene nanosheets exhibit a typical wrinkled structure, which results from stable bending thermodynamically. ${ }^{42,43}$

Figures 2(c-d) show SEM images of the $\mathrm{NiFe}_{2} \mathrm{O}_{4}$ and $\mathrm{NiFe}_{2} \mathrm{O}_{4}-\mathrm{NG}$ samples where as Figures 3(c-d) show TEM images of the $\mathrm{NiFe}_{2} \mathrm{O}_{4}$ and $\mathrm{NiFe}_{2} \mathrm{O}_{4}-\mathrm{NG}$ samples. In Figure $2 \mathrm{c}$ and Figure $3 \mathrm{c}, \mathrm{NiFe}_{2} \mathrm{O}_{4}$ nanoparticles are clear-
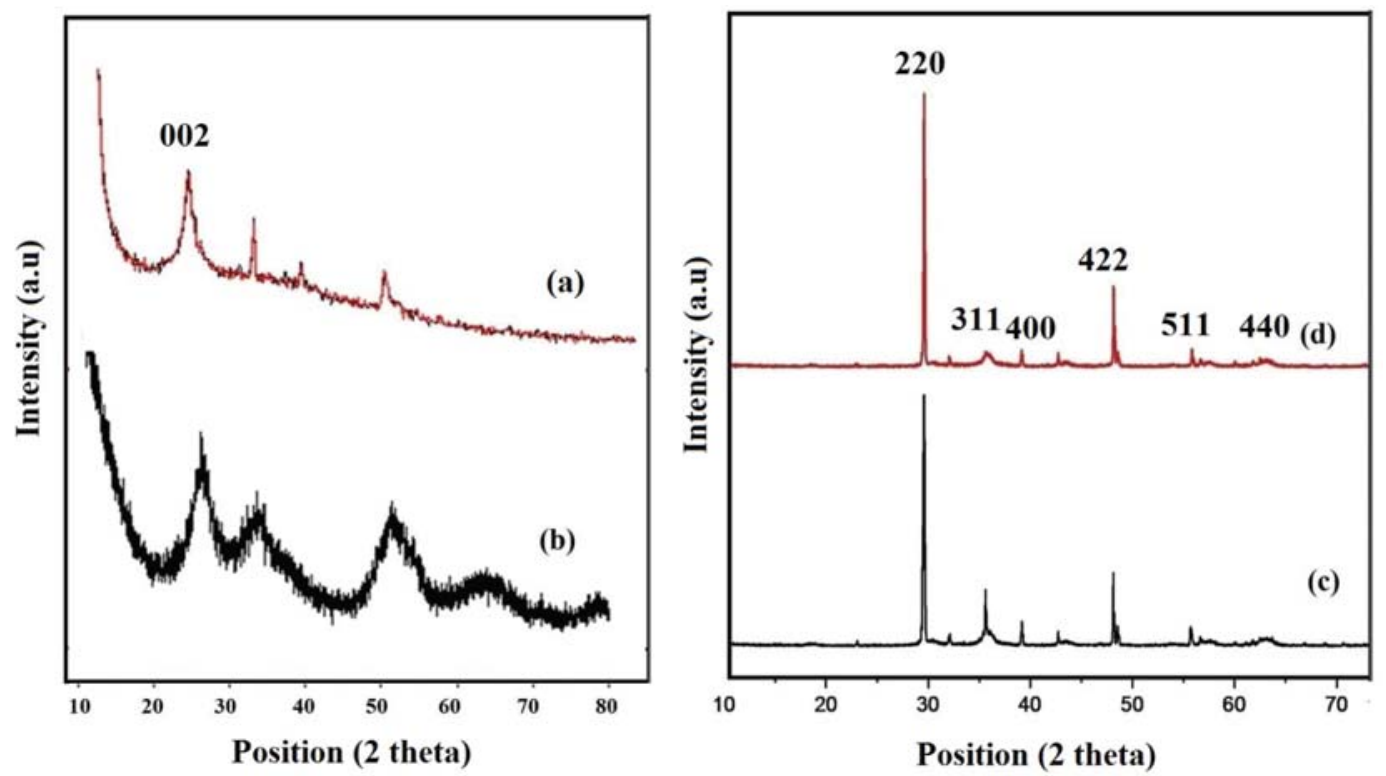

Figure 1. PXRD patterns of (a) $\mathrm{GO}$, (b) $\mathrm{NG}$, (c) $\mathrm{NiFe}_{2} \mathrm{O}_{4}$ and (d) $\mathrm{NiFe}_{2} \mathrm{O}_{4}-\mathrm{NG}$. 

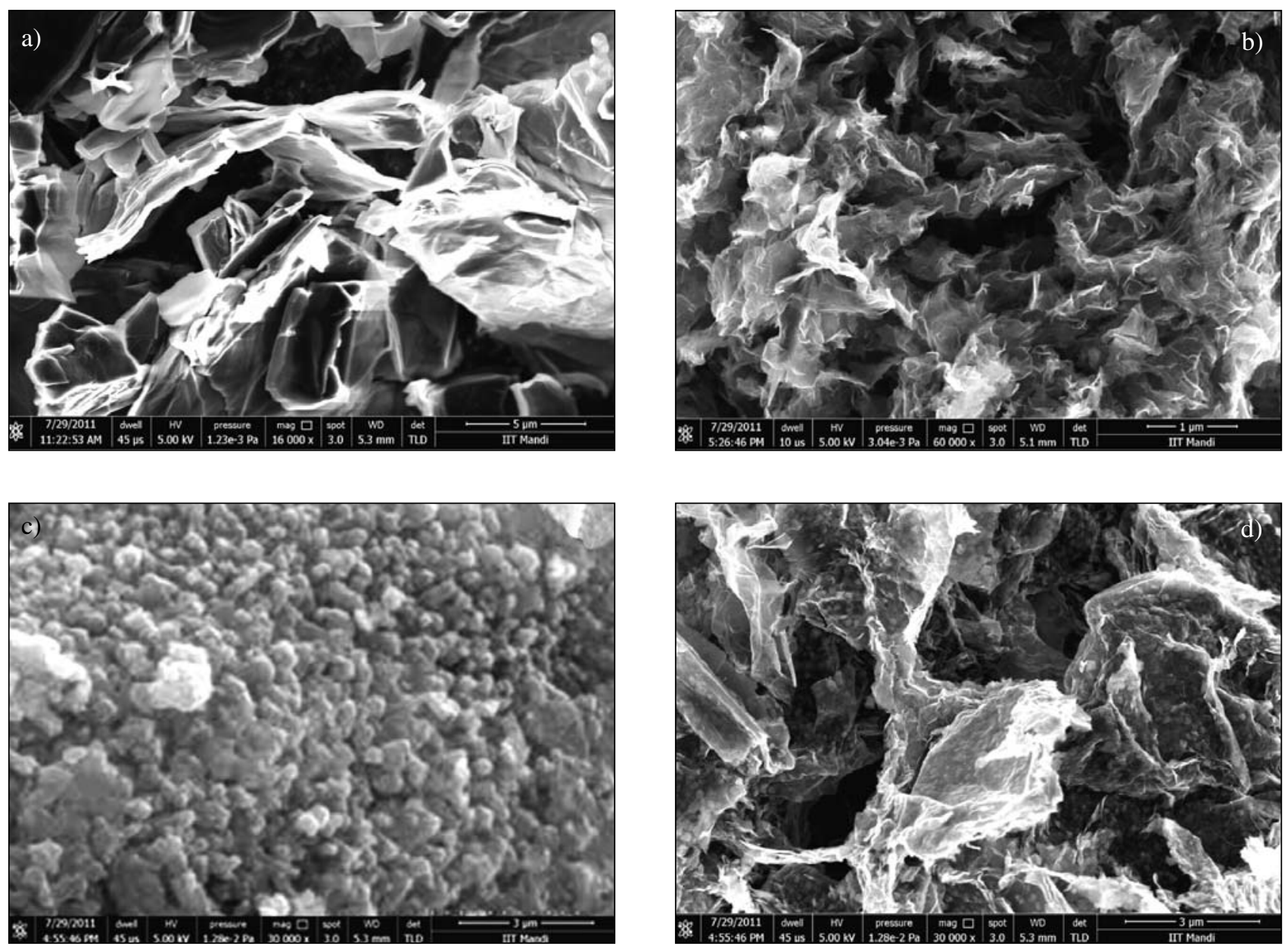

Figure 2. $\mathrm{SEM}$ images of (a) $\mathrm{GO}$ (b) $\mathrm{NG}$ (c) $\mathrm{NiFe}_{2} \mathrm{O}_{4}$ and (d) $\mathrm{NiFe}_{2} \mathrm{O}_{4}-\mathrm{NG}$.

ly visible in the SEM and TEM images. The $\mathrm{NiFe}_{2} \mathrm{O}_{4}$ nanoparticles distributed on NG to form nanoparticles bound on the surface of NG sheets is seen in the Figure 2d and Figure 3d. Measurements showed that the average diameter of $\mathrm{NiFe}_{2} \mathrm{O}_{4}-\mathrm{NG}$ particles is approximately 80 $\mathrm{nm}$. The particle size data obtained from TEM data are in very close agreement to the size calculated from the Debye-Scherrer method.

\section{3. FT-IR Characterization}

Figure 4(a-d) shows the FTIR spectra of GO, NG, $\mathrm{NiFe}_{2} \mathrm{O}_{4}$ and $\mathrm{NiFe}_{2} \mathrm{O}_{4}-\mathrm{NG}$. There are many O-containing groups that exist on GO sheets, such as hydroxyl, epoxy, and carboxyl groups. Majority of the O-containing groups will disappear after reduction. FTIR bands at $1050,1220,1405$ and $1730 \mathrm{~cm}^{-1}$ were observed for GO. These bands correspond to $\mathrm{C}-\mathrm{O}$ stretching, $\mathrm{C}-\mathrm{O}-\mathrm{C}$ stretching, $\mathrm{O}-\mathrm{H}$ deformation vibration and $\mathrm{C}=\mathrm{O}$ carbonyl stretching. ${ }^{44}$ FTIR bands at $1400 \mathrm{~cm}^{-1}$ due to $\mathrm{C}=\mathrm{C}$ stretching is observed in $\mathrm{NG}$ and the $\mathrm{vC}=\mathrm{O}$ band at 1730 $\mathrm{cm}^{-1}$ completely disappeared due to reduction. The bands located at 1180 and $1565 \mathrm{~cm}^{-1}$ in Figure $4 \mathrm{~b}$ are assigned to the $\vee \mathrm{C}-\mathrm{N}$ and $\vee \mathrm{C}=\mathrm{C}$ respectively. The FTIR spectra suggest $\mathrm{N}$ doping of GO. Figure $4(\mathrm{c}-\mathrm{d})$ shows the FT-IR bands of $\mathrm{NiFe}_{2} \mathrm{O}_{4}$ and $\mathrm{NiFe}_{2} \mathrm{O}_{4}-\mathrm{NG}$. The bands observed in the range of $620-650 \mathrm{~cm}^{-1}$ corresponds to the intrinsic stretching vibrations of the $\mathrm{M}-\mathrm{O}$ in the tetrahedral site. The second band around 3400-3500 $\mathrm{cm}^{-1}$ corresponds to $\mathrm{O}-\mathrm{H}$ stretching vibrations. ${ }^{45}$ Furthermore, it is observed that almost all the characteristic bands of oxygen containing functional groups $(\mathrm{C}=\mathrm{O}$, $\mathrm{O}-\mathrm{H}, \mathrm{C}-\mathrm{OH}$ and $\mathrm{C}-\mathrm{O}-\mathrm{C})$ disappeared in the FT-IR spectrum of $\mathrm{NiFe}_{2} \mathrm{O}_{4}-\mathrm{NG}$ depicting the change in the surface morpholgy of $\mathrm{NG}-\mathrm{NiFe}_{2} \mathrm{O}_{4}$ composite. These findings show that $\mathrm{NiFe}_{2} \mathrm{O}_{4}$ nanoparticles are bonded to the NG. The results above show the heteroatom $\mathrm{N}$ was entered in the graphene structure and the $\mathrm{NiFe}_{2} \mathrm{O}_{4}-\mathrm{NG}$ composites was prepared favourably.

\section{4. Photocatalytic Measurements}

The adsorption of light by the photocatalysts is the key feature of photocatalysis method. Figure 5a show the 

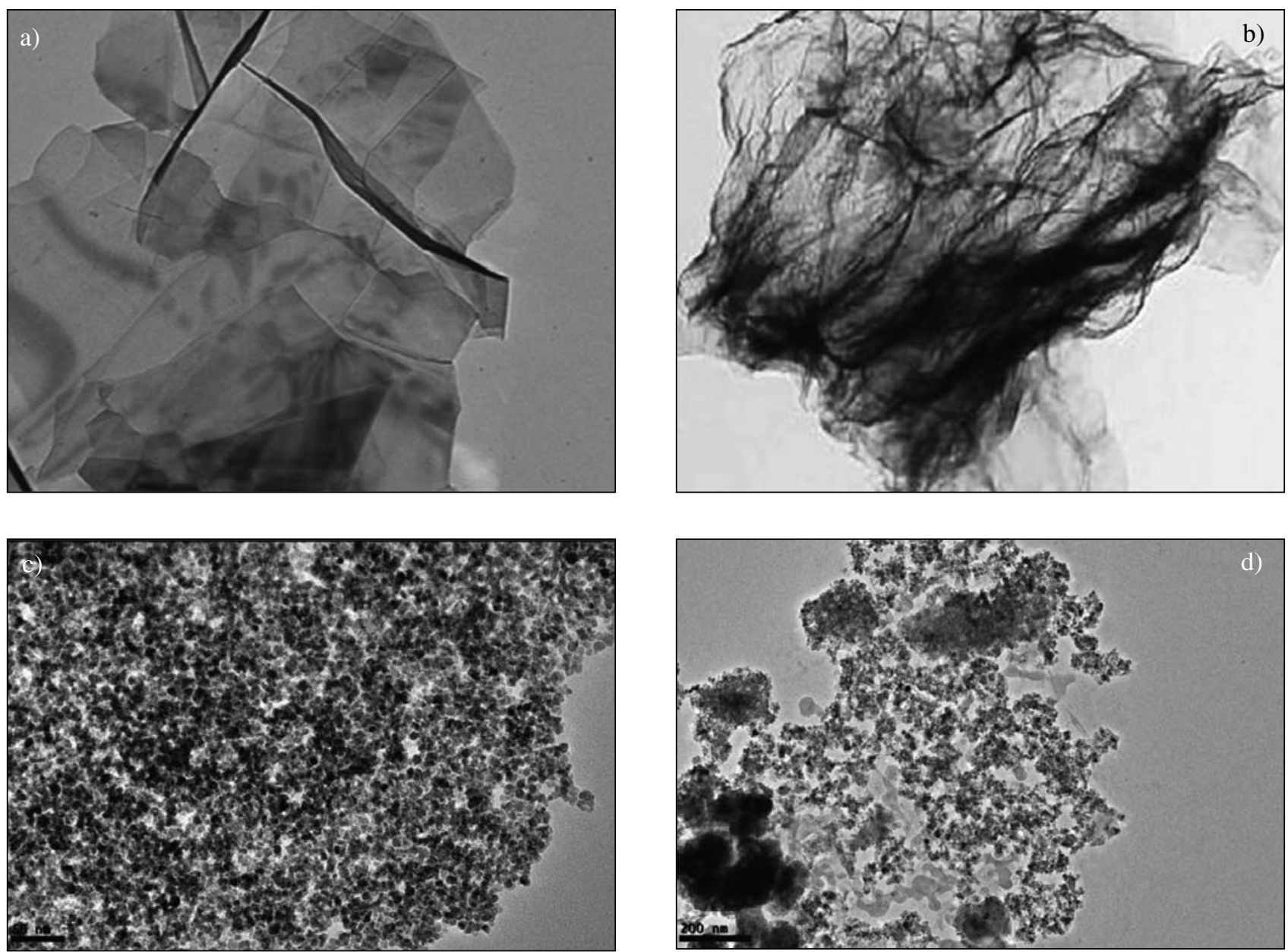

Figure 3. TEM images of (a) GO, (b) $\mathrm{NG}$, (c) $\mathrm{NiFe}_{2} \mathrm{O}_{4}$ and (d) $\mathrm{NiFe}_{2} \mathrm{O}_{4}-\mathrm{NG}$

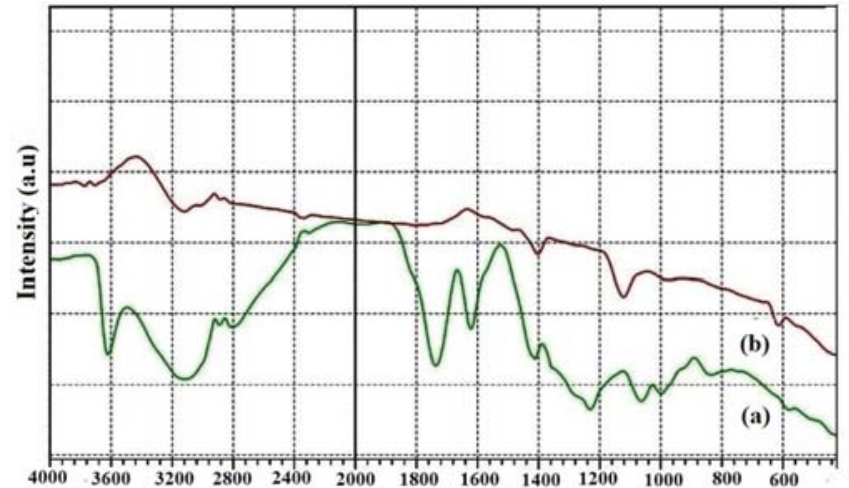

Wave number $\left(\mathrm{cm}^{-1}\right)$

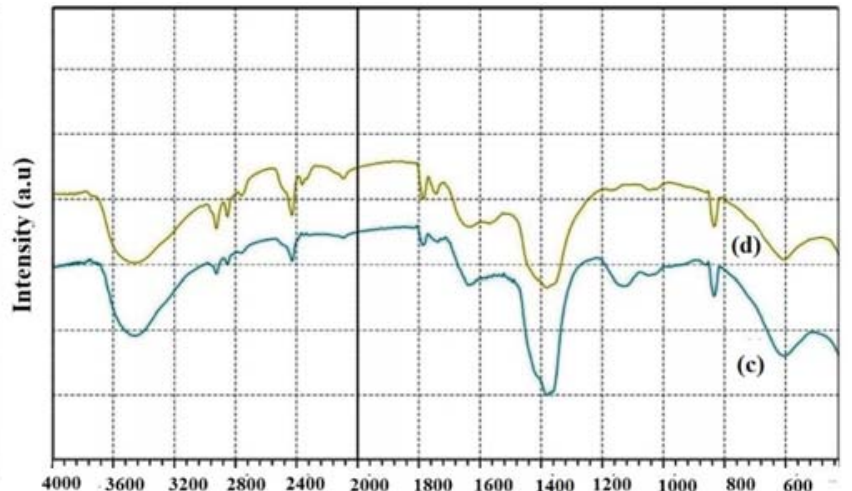

Wave number $\left(\mathrm{cm}^{-1}\right)$

Figure 4. FT-IR spectra of (a) $\mathrm{GO}$ (b) $\mathrm{NG}$ (c) $\mathrm{NiFe}_{2} \mathrm{O}_{4}$ (d) $\mathrm{NiFe}_{2} \mathrm{O}_{4}-\mathrm{NG}$

UV Spectrum of $\mathrm{NiFe}_{2} \mathrm{O}_{4}-\mathrm{NG}$. The photocatalytic activities of the as-obtained $\mathrm{NiFe}_{2} \mathrm{O}_{4}-\mathrm{NG}$ nanocomposite photocatalysts were evaluated by monitoring the degradation of methylene blue (MB) under visible-light irradiation at $25^{\circ} \mathrm{C}$. Figure 5 a shows the changes in the absorbance pro- files of $\mathrm{MB}$ solution (concentration of $\mathrm{MB}, \mathrm{C}=0.075 \mathrm{M}$ and path length, $\mathrm{I}=1 \mathrm{~cm})$ in the presence of $\mathrm{NiFe}_{2} \mathrm{O}_{4}-\mathrm{NG}$ photocatalyst under visible-light irradiated at $25^{\circ} \mathrm{C}$ recorded at different time intervals. The adsorption-desorption equilibriated solution of $\mathrm{MB}$ and $\mathrm{NiFe}_{2} \mathrm{O}_{4}-\mathrm{NG}$ was used 


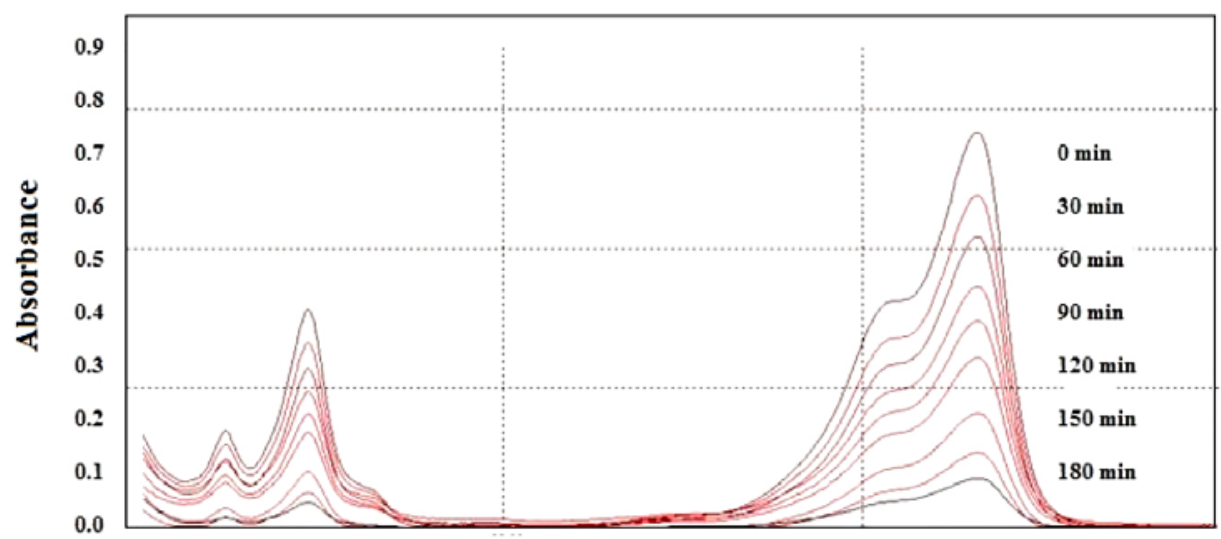

Wavelength (nm)

Figure 5a. Absorption spectra of the $\mathrm{MB}$ solution $(\mathrm{C}=0.075 \mathrm{M}$ and $\mathrm{I}=1 \mathrm{~cm})$ taken at different photocatalytic degradation times using Ni$\mathrm{Fe}_{2} \mathrm{O}_{4}$-NG.

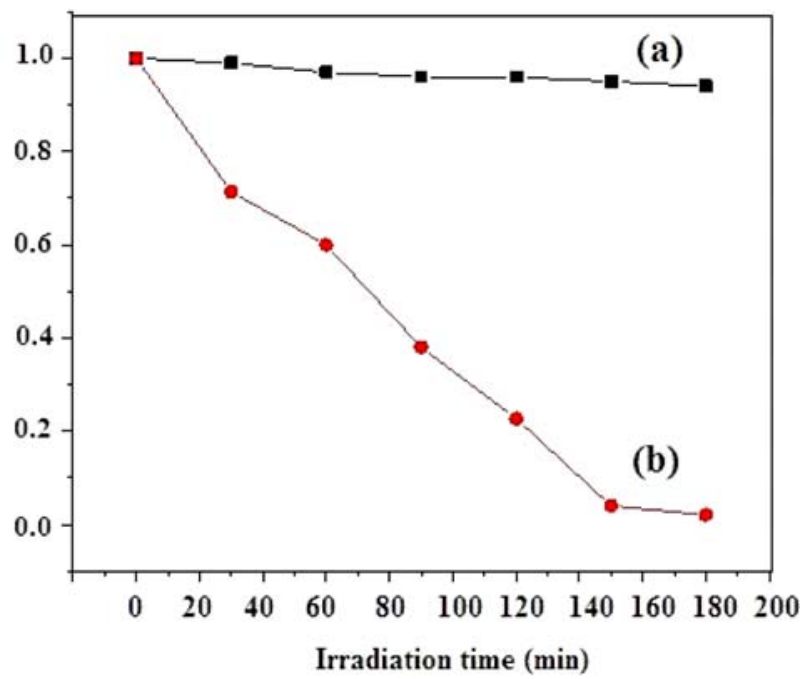

Figure 5b. Kinetics of photodegradation of (a) Pure MB and (b) the pure MB solution. The catalyst acts as magnetic material which gives good performance in magnetic separation for the $\mathrm{NiFe}_{2} \mathrm{O}_{4}-\mathrm{NG}$ photocatalysts using an external magnet.

\section{4. 1. Mechanism of Photocatalytic Activity Measurements}

The photocatalytic activity for MB degradation can be best explained by the following mechanism. The notable increase in photocatalytic activity under visible light exposure can be attributed to exceptional synergistic effect between $\mathrm{NiFe}_{2} \mathrm{O}_{4}$ and the nitrogen-doped graphene sheets causing the effective separation of carriers generated by the light exposure in the $\mathrm{NiFe}_{2} \mathrm{O}_{4}-\mathrm{NG}$ composite system. A plausible mechanism for enhancement in photocatalysis process is shown as follows:

When the visible-light is irradiated on the surface of

$$
\begin{aligned}
& \mathrm{NiFe}_{2} \mathrm{O}_{4}+\text { Visible light } \\
& \mathrm{NiFe}_{2} \mathrm{O}_{4}(\mathrm{e})+\mathrm{N} \text {-doped graphene } \\
& \mathrm{N} \text {-doped graphene }(\mathrm{e})+\mathrm{NiFe}_{2} \mathrm{O}_{4}(\mathrm{~h}+\mathrm{e}) \\
& \mathrm{NiFe}_{2} \mathrm{O}_{4}(\mathrm{~h})+\mathrm{OH}^{-} \longrightarrow \mathrm{NiFe}_{2} \mathrm{O}_{4}+\mathrm{N} \text {-doped graphene }
\end{aligned}
$$

as starting solution. In Figure $5 \mathrm{~b} \mathrm{C} / \mathrm{C}_{0}$ was plotted versus time where $\mathrm{C}_{0}$ is initial concentration of methylene blue $(0.075 \mathrm{M}$ at time $\mathrm{t}=0 \mathrm{~min}$. and $\mathrm{C}$ is concentration at time $\mathrm{t}$ min.). It can be clearly seen that almost all the $\mathrm{MB}$ in the solution is decomposed after $180 \mathrm{~min}$ in presence of the $\mathrm{NiFe}_{2} \mathrm{O}_{4}-\mathrm{NG}$ while there is least photodegradation in
$\mathrm{NiFe}_{2} \mathrm{O}_{4}$, the electron-hole pairs are formed (Eq. 2). Then by the percolation mechanism, the electrons generated by the photogeneration process are instantly transfer onto NG sheets (Eq. 3). Superoxide anion radical is produced from oxygen dissolved and activated through nitrogen doped graphene carrying negative charge (Eq. 4). The adsor- 
bed water can react with holes to produce hydroxyl radical (Eq. 5). At the end superoxide anion, and hydroxyl radical cause the oxidation of MB dye adsorbed on the surface of $\mathrm{NiFe}_{2} \mathrm{O}_{4}-\mathrm{NG}$ composite by electrostatic interaction and $\pi$ $\pi$ interaction between aromatic rings of methylene blue and graphene layer (Eq. 6). In the photocatalytic degradation process, the electrons of the photocatalyst i,e Ni$\mathrm{Fe}_{2} \mathrm{O}_{4}$-NG nanocomposite are excited from the valence band (VB) to the conduction band (CB) by the visible light irradiation. The photogenerated holes in the VB are scavenged by $\mathrm{OH}^{-}$of water forming $\mathrm{OH}$ radicals which are responsible for the $\mathrm{MB}$ degradation process afterwards. The $\mathrm{N}$-graphene performs two functions; (a) it acts as charge carrier to trap the delocalised electrons thereby restricting the (h-e) recombination. (b) Secondly, it increases the adsorption of MB dye on the catalyst surface thereby increasing the $\pi-\pi$ interaction between aromatic rings of methylene blue and graphene layer. ${ }^{46}$

\section{5. Magnetic Characterization}

Magnetization hysteresis loops of the as-prepared $\mathrm{NiFe}_{2} \mathrm{O}_{4}$ and $\mathrm{NiFe}_{2} \mathrm{O}_{4}-\mathrm{NG}$ samples at room temperature were measured using vibrating sample magnetometer as shown in Figure $6(\mathrm{a}-\mathrm{b})$. The magnetic properties of the $\mathrm{NiFe}_{2} \mathrm{O}_{4}$ having inverse spinel structure can be described in terms of cations distribution. The magnetization originates from the $\mathrm{Fe}^{3+}$ ions at both tetrahedral and octahedral sites and $\mathrm{Ni}^{2+}$ is present only in octahedral sites. ${ }^{47,48}$ Coercivity and saturation magnetization of $\mathrm{NiFe}_{2} \mathrm{O}_{4}-\mathrm{NG}$ are $47.4 \mathrm{G}$ and $10.1 \mathrm{emu} / \mathrm{g}$ respectively, whereas that of $\mathrm{Ni}$ $\mathrm{Fe}_{2} \mathrm{O}_{4}$ are $33.5 \mathrm{G}$ and $9.2 \mathrm{emu} / \mathrm{g}$ respectively. The values observed for $\mathrm{NiFe}_{2} \mathrm{O}_{4}-\mathrm{NG}$ are larger than those for Ni$\mathrm{Fe}_{2} \mathrm{O}_{4}$ which shows that $\mathrm{NiFe}_{2} \mathrm{O}_{4}-\mathrm{NG}$ is more easily separable than $\mathrm{NiFe}_{2} \mathrm{O}_{4}$. The increase in the saturation magne-

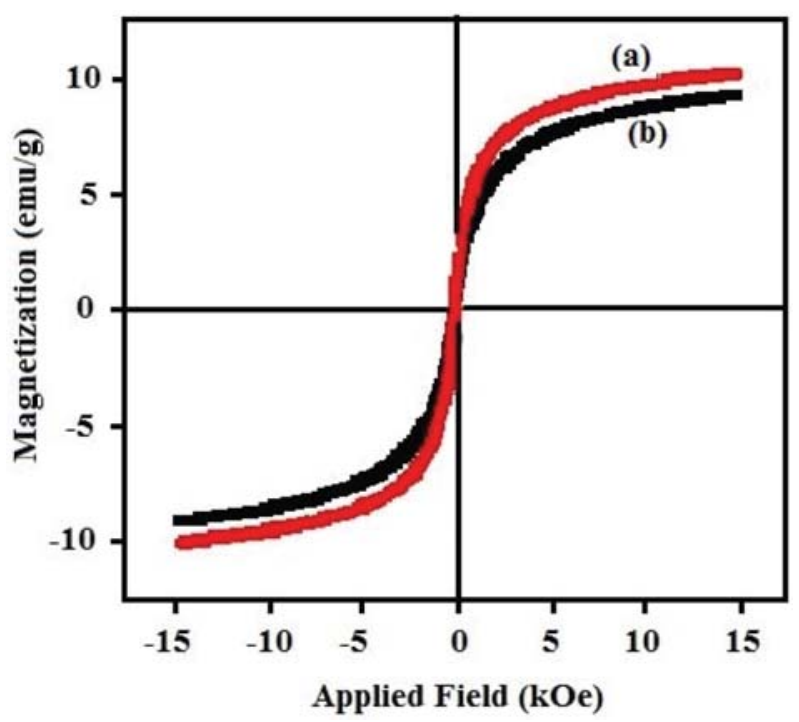

Figure 6. Magnetic hysteresis loop measured at $300 \mathrm{~K}$ for (a) Ni$\mathrm{Fe}_{2} \mathrm{O}_{4}$ (b) $\mathrm{NiFe}_{2} \mathrm{O}_{4}-\mathrm{NG}$ tization was possibly attributed to the increasing crystallinity and particle size of the nanoparticles.

\section{Conclusions}

In the outcome, a magnetic $\mathrm{NiFe}_{2} \mathrm{O}_{4}-\mathrm{NG}$ photocatalyst has been fabricated through hydrothermal route. The SEM and TEM images show that nitrogen-doped graphene sheets are flaked and furnished with $\mathrm{NiFe}_{2} \mathrm{O}_{4}$ nanoparticles having an average diameter of $80 \mathrm{~nm}$. The photocatalytic activity measurements confirm that the Ni$\mathrm{Fe}_{2} \mathrm{O}_{4}$ nanoparticles combined with nitrogen-doped graphene sheets lead to exciting conversion of the inactive $\mathrm{Ni}$ $\mathrm{Fe}_{2} \mathrm{O}_{4}$ into very good catalyst for the degradation of methylene blue (MB) under visible light irradiation. The notable increase in photoactivity can be ascribed to the superior conductivity of the reduced NG sheets leading to favourable and efficient separation of photogenerated carriers (hole-electron) in the $\mathrm{NiFe}_{2} \mathrm{O}_{4}-\mathrm{NG}$ system. Subsequently, there is very large and useful change in photocatalytic activity after coupling nickel ferrite with nitrogendoped graphene sheets.

\section{Acknowledgements}

We would like to acknowledge SAIF, Panjab University, Chandigarh and Indian Institute of Technology Guwahati for their technical support. We thank Indian Institute of Technology Mandi for powder X-ray diffraction study.

\section{References}

1. M. R. Hoffmann, S. T. Martin, W. Choi, D. W. Bahnemann, Chem. Rev. 1995, 95, 69-96. https://doi.org/10.1021/cr00033a004

2. B. Mahrov, G. Boschloo, A. Hagfeldt, L. Dloczik, T. Dittrich, Appl. Phys. Lett. 2004, 84, 5455-5457. https://doi.org/10.1063/1.1767961

3. A. Hattori, Y. Tokihisa, H. Tada, S. Ito, J. Electrochem. Soc. 2000, 147, 2279-2283. https://doi.org/10.1149/1.1393521

4. G. K. Ropidas, M. Bohorquez, P. V. Kamat, J. Phys. Chem. 1990, 94, 6435-6440. https://doi.org/10.1021/j100379a051

5. Z. J. Zhang, W. Z. Wang, W. Z. Yin, M. Shang, L. Wang, S. M. Sun, Appl. Catal. B 2010, 10, 68-73. https://doi.org/10.1016/j.apcatb.2010.09.008

6. B. K. Vijayan, N. M. Dimitrijevic, J. S. Wu, K. A. Gray, J. Phys. Chem. C 2010, 114, 21262-21269. https://doi.org/10.1021/jp108659a

7. X. Shu, J. He, D. Chen, Ind. Eng. Chem. Res. 2008, 47, 4750-4753. https://doi.org/10.1021/ie071619d 
8. K. S. Novoselov, A. K. Geim, S. V. Morozov, D. Jiang, Y. Zhang, S. V. Dubonos, I. V. Grigorieva, A. A. Firsov, Science 2004, 306, 666-669. https://doi.org/10.1126/science.1102896

9. A. K. Geim, Science 2009, 324, 1530-1534. https://doi.org/10.1126/science.1158877

10. S. Chen, J. Zhu, X. Wang, ACS Nano 2010, 4, 6212-6218. https://doi.org/10.1021/nn101857y

11. Y. M. Li, X. J. Lv, J. Lu, J. Li, J. Phys. Chem. C 2010, 114, 2177-21774.

12. O. Akhavan, ACS Nano 2010, 4, 4174-4180. https://doi.org/10.1021/nn1007429

13. K. S. Novoselov, A. K. Geim, S. V. Morozov, D. Jiang, M. I. Katsnelson, I. V. Grigorieva, S. V. Dubonos, A. A. Firsov, Nature 2005, 438, 197-200. https://doi.org/10.1038/nature04233

14. J. Sakamoto, J. van Heijst, O. Lukin, A. D. Schluter, Angew. Chem. Int. Ed. 2009, 48, 1030-1069. https://doi.org/10.1002/anie.200801863

15. M. Burghard, H. Klauk, K. Kern, Adv. Mater. 2009, 21, 2586-2600. https://doi.org/10.1002/adma.200803582

16. R. Devi, G. Prabhavathi, R. Yamuna, S. Ramakrishanan, N. K. Kothurkar, J. Chem. Sci. 2014, 126, 75-83. https://doi.org/10.1007/s12039-013-0536-1

17. H. Zhang, X. Lv, Y. Li, Y. Wang, J. Li, ACS Nano 2010, 4, 380-386. https://doi.org/10.1021/nn901221k

18. G. Williams, B. Seger, P. V. Kamat, ACS Nano 2008, 2, 1487-1491. https://doi.org/10.1021/nn800251f

19. Y. Zhang, Z. R. Tang, X. Fu, Y. J. Xu, ACS Nano 2010, 4, 7303-7314. https://doi.org/10.1021/nn1024219

20. D. H. Yoo, V. C. Tran, V. H. Pham, J. S. Chung, N. T. Khoa, E. J. Kim, S. H. Hahn, Curr. Appl. Phys. 2011, 11, 805-808. https://doi.org/10.1016/j.cap.2010.11.077

21. O. Akhavan, Carbon 2011, 49, 11-18. https://doi.org/10.1016/j.carbon.2010.08.030

22. T. G. Xu, L. W. Zhang, H. Y. Cheng, Y. F. Zhu, Appl. Catal. B 2011, 101, 382-387. https://doi.org/10.1016/j.apcatb.2010.10.007

23. S. Shylesh, V. Schunemann, W. R. Thiel, Angew. Chem. Int. Ed. 2010, 49, 3428-3459. https://doi.org/10.1002/anie.200905684

24. H. Zhang, S. Gao, N. Shang, C. Wang, Z. Wang, RSC Adv. 2014, 4, 31328-31332.

25. N. Velinov, K. Koleva, T. Tsoncheva, D. Paneva, E. Manova, K. Tenchev, B. Kunev, I. Genova, I. Mitov, Cent. Eur. J. Chem. 2014, 12, 250-259. https://doi.org/10.2478/s11532-013-0371-8

26. B. I. Kharisov, H. V. R. Dias, O. V. Kharissova, A. J. Chem. 2014, DOI: $10.1016 /$ j.arabjc.2014.10.049. https://doi.org/10.1016/j.arabjc.2014.10.049

27. Y. Fu, Q. Chen, M. He, Y. Wan, X. Sun, H. Xia, X. Wang, Ind. Eng. Chem. Res. 2012, 51, 11700-11709. https://doi.org/10.1021/ie301347j
28. C. U. Aniz, T. D. R. Nair, OJPC, 2011, 1, 124-130. https://doi.org/10.4236/ojpc.2011.13017

29. N. Rezlescu, E. Rezlescu, P. D. Popa, C. Doroftei, M. Ignat, Romanian Reports in Physics, 2013, 65, 1348-1356.

30. Y. Kinemuchi, K. Ishizaka, H. Suematsu, W. H. Jiang, K. Yatsui, Thin Solid Films 2002, 407, 109-113. https://doi.org/10.1016/S0040-6090(02)00021-4

31. Y. S. Chung, S. B. Park, D. W. Kang, Mater. Chem. Phys. 2004, 86, 375-381. https://doi.org/10.1016/j.matchemphys.2004.03.027

32. Rahmayeni, S. Arief, Y. Stiadi, R. Rizal, Zulhadjri, Indo. J. Chem. 2012, 12, 229-234.

33. Y. S. Fu, X. Wang, Ind. Eng. Chem. Res. 2011, 50, 72107218. https://doi.org/10.1021/ie200162a

34. H. Guo, Q. Gao, J. Power Sources 2009, 186, 551-556. https://doi.org/10.1016/j.jpowsour.2008.10.024

35. L. Zhao, L. Fan, M. Zhou, H. Guan, S. Qiao, M. Antonietti, M. Titirici, Adv. Mater. 2010, 22, 5202-5206. https://doi.org/10.1002/adma.201002647

36. L. Chen, X. Zhang, H. Liang, M. Kong, Q. Guan, P. Chen, Z. Wu, S. Yu, ACS Nano 2012, 6, 7092-7102. https://doi.org/10.1021/nn302147s

37. J. Xu, G. Dong, C. Jin, M. Huang, L. Guan, ChemSusChem 2013, 6, 493-499. https://doi.org/10.1002/cssc.201200564

38. S. Bag, C. R. Raj, J. Chem. Sci. 2016, 128, 339-347. https://doi.org/10.1007/s12039-016-1034-z

39. W. S. Hummers R. E. Offeman J. Am. Chem. Soc. 80 (1958) 1339-1339. https://doi.org/10.1021/ja01539a017

40. A. I. Vogel, A Textbook of Quantitative Inorganic Analysis, forth ed., Longman, London, 1978.

41. D. C. Marcano, D. V. Kosynkin, J. M. Berlin, A. Sinitskii, Z. Sun, A. Slesarev, L. B. Alemany, W. Lu, J. M. Tour, ACS Nano 2010, 4, 4806-4814. https://doi.org/10.1021/nn1006368

42. Y. Fu, H. Chen, X. Sun, X. Wang, AIChE J. 2012, 58, 32983305. https://doi.org/10.1002/aic.13716

43. X. Zheng, Q. Xu, L. He, N. Yu, S. Wang, Z. Chen, J. Phys. Chem. B 2011, 115, 5815-5826. https://doi.org/10.1021/jp2018082

44. M. Acik, C. Mattevi, C. Gong, G. Lee, K. Cho, M. Chhowalla, ACS Nano 2010, 10, 5861-5868. https://doi.org/10.1021/nn101844t

45. D. Du, P. Li, J. Ouyang, ACS Appl. Mater. Interfaces 2015, 7 , 26952-26958. https://doi.org/10.1021/acsami.5b07757

46. L. Gan, L. Xu, S. Shang, X. Zhou, L. Meng, Ceram. Int. 2016, 42, 15235-15241. https://doi.org/10.1016/j.ceramint.2016.06.160

47. H. Nathani, S. Gubbala, R. D. K. Misra, Mater. Sci. Eng. B 2005, 121, 126-136. https://doi.org/10.1016/j.mseb.2005.03.016

48. A. B. Nawale, N. S. Kanhe, K. R. Patil, S. V. Bhoraskar, V. L. Mathe, A. K. Das, J Alloys Compd. 2011, 509, 4404-4413. https://doi.org/10.1016/j.jallcom.2011.01.057 


\section{Povzetek}

Preprost sintezni način smo uporabili za pripravo magnetnega fotokatalizatorja $\mathrm{NiFe}_{2} \mathrm{O}_{4}$ na grafenu, dopiranem $\mathrm{z}$ dušikom (NG). Kompozit $\mathrm{NiFe}_{2} \mathrm{O}_{4}-\mathrm{NG}$ smo pripravili z enostopenjsko hidrotermalno sintezo. Nanokompozitni katalizator smo karakterizirali z naslednjimi metodami: rentgensko praškovno difrakcijo (XRD), vrstično elektronsko mikroskopijo (SEM), presevno elektronsko mikroskopijo (TEM), infrardečo spektroskopijo (FT-IR), UV-Vis spektroskopijo in magnetometrijo z vibrirajočim vzorcem (VSM). Kombinacija nanodelcev $\mathrm{NiFe}_{2} \mathrm{O}_{4}$ in grafena, dopiranega $\mathrm{z}$ dušikom pretvori $\mathrm{NiFe}_{2} \mathrm{O}_{4} \mathrm{v}$ dober katalizator za fotokatalitični razpad barvila metilen modro (MB). Fotokatalitično aktivnost pod vplivom vidne svetlobe lahko pripišemo obsežnemu premiku vzbujenih elektronov iz $\mathrm{NiFe}_{2} \mathrm{O}_{4} \mathrm{v}$ prevodni pas reduciranega grafena (NG). Že sami nanodelci $\mathrm{NiFe}_{2} \mathrm{O}_{4}$ imajo takšne magnetne lastnosti, da jih lahko uporabimo za magnetno separacijo $\mathrm{v}$ raztopini brez dodatne uporabe magneta. 